\title{
Edu Sportivo
}

Indonesian Journal of Physical Education

e-ISSN 2745-942X

Journal Homepage: https://journal.uir.ac.id/index.php/SPORTIVO

\section{Manajemen National Paralympic Committee (NPC) dalam pembinaan prestasi atlet penyandang disabilitas}

\section{Management of the National Paralympic Committee (NPC) in coaching the achievements of athletes with disabilities}

\author{
${ }^{* 1}$ Dini Rahmawati, ${ }^{2}$ Agus Wiyanto, ${ }^{3}$ Danang Aji Setyawan \\ *1,2,3Program Studi Pendidikan Jasmani Kesehatan dan Rekreasi, Universitas PGRI Semarang, Semarang, \\ Indonesia
}

Received: 02 October 2020; Accepted 03 December 2020; Published 05 December 2020

OPEN2ACCESS

\begin{tabular}{|c|c|}
\hline ABSTRAK & ABSTRACT \\
\hline $\begin{array}{l}\text { Prestasi yang ditorehkan oleh penyandang disabilitas } \\
\text { melalui bidang olahraga memang cukup menarik untuk } \\
\text { dikaji dan dicermati, tujuan penelitian ini untuk } \\
\text { menganalisis manajemen prestasi disabilitas dan faktor } \\
\text { pendukung dan penghambat dalam pembinaan atlet } \\
\text { disabilitas pada NPC kabupaten Kendal. Desain penelitian } \\
\text { yang digunakan adalah penelitian Kualitatif, Teknik } \\
\text { pengumpulan data meliputi: (1) observasi, (2) wawancara, } \\
\text { (3) dan dokumentasi, dengan subyek penelitian terdiri dari: } \\
\text { (1) Kepala NPC Kabupaten Kendal, (2) Seksi Pemberdayaan } \\
\text { Atlet, (3) Seksi Cabang Olahraga, (4) Atlet Paralympic. } \\
\text { Proses penyaringan atlet melalui kerjasama dengan guru } \\
\text { olahraga SLB dan Tim dari NPC. Pengawasan yang } \\
\text { dilakukan oleh National Paralympic Committe (NPC) dari } \\
\text { memantau kondisi atlet, tempat kerja atletnya dan keluarga } \\
\text { atletnya agar paham bahwa atlet tersebut berprestasi. } \\
\text { Kesimpulan dalam penelitian ini, NPC dapat meningkatkan } \\
\text { penguatan organisasi melalui rapat koordinasi, } \\
\text { memfasilitasi organisasi serta pelaksanaan pembinaan } \\
\text { melalui dana hibah dari Pemerintah Daerah. Pembinaan } \\
\text { prestasi atlet disabilitas NPC melakukan penyaringan ke } \\
\text { SLB guna mencari bibit atlet yang berpotensi, serta untuk } \\
\text { lebih memperhatikan sarana dan prasarana untuk } \\
\text { menunjang pembinaan prestasi agar atlet disabilitas dapat } \\
\text { mencapai prestasi. }\end{array}$ & $\begin{array}{l}\text { The achievements made by persons with disabilities through } \\
\text { sports are indeed quite interesting to study and observe, the } \\
\text { purpose of this study is to analyze disability achievement } \\
\text { management and supporting and inhibiting factors in the } \\
\text { development of athletes with disabilities in the Kendal district } \\
\text { NPC. The research design used is qualitative research, data } \\
\text { collection techniques include: (1) observation, (2) interviews, } \\
\text { (3) and documentation, with research subjects consisting of: } \\
\text { (1) The Head of the Kendal Regency NPC, (2) Athlete } \\
\text { Empowerment Section, (3) Sports Section, (4) Paralympic } \\
\text { Athletes. The process of screening athletes in collaboration } \\
\text { with sports teachers from special schools and teams from the } \\
\text { NPC. Supervision is carried out by the National Paralympic } \\
\text { Committee (NPC) from monitoring the condition of the } \\
\text { athlete, the place where the athlete works and the athlete's } \\
\text { family so that they understand that the athlete is performing. } \\
\text { The conclusion in this study, NPC can increase organizational } \\
\text { strengthening through coordination meetings, facilitate } \\
\text { organization and implementation of guidance through grants } \\
\text { from the Regional Government. Performance development for } \\
\text { athletes with disabilities NPC conducts screening to special } \\
\text { schools in order to find potential athletes, as well as to pay } \\
\text { more attention to facilities and infrastructure to support } \\
\text { performance development so that athletes with disabilities } \\
\text { can achieve achievements. }\end{array}$ \\
\hline $\begin{array}{l}\text { Kata Kunci: Manajemen; National Paralympic Committe; } \\
\text { Disabilitas }\end{array}$ & $\begin{array}{l}\text { Keyword: Management; National Paralympic Committee; } \\
\text { Disabilities }\end{array}$ \\
\hline $\begin{array}{l}\text { *Corresponding Author } \\
\text { Email: dinirhm16@gmail.com }\end{array}$ & doi https://doi.org/10.25299/es:ijope.2020.vol1(2).5661 \\
\hline
\end{tabular}

How To Cite: Rahmawati, D., Wiyanto, A., \& Setyawan, D. A. (2020). Manajemen National Paralympic Committee (NPC) dalam pembinaan prestasi atlet penyandang disabilitas. Edu Sportivo: Indonesian Journal of Physical Education, 1(2), 97-102. https://doi.org/10.25299/es:ijope.2020.vol1(2).5661 


\section{PENDAHULUAN}

Seiring dengan perkembangan zaman, kegiatan yang menunjang kondisi fisik menjadi hal yang sangat diperlukan (Sari \& Antoni 2020). Perkembangan olahraga di Indonesia sekarang ini terasa semakin maju, hal ini tidak terlepas dari peran serta masyarakat yang semakin sadar dan mengerti arti penting fungsi olahraga itu sendiri, di samping adanya perhatian serta dukungan pemerintah juga menunjang perkembangan olahraga di Indonesia (Rusmanto, Lardika, \& Muspita, 2020). Undang-undang Sistem Keolahragaan (UU No 3 Tahun 2005) pasal 1 tentang keolahragaan disebutkan bahwa Keolahragaan adalah segala aspek yang berkaitan dengan olahraga yang memerlukan pengaturan, pendidikan, pelatihan, pembinaan, pengembangan, dan pengawasan. Kresnapati (2020) menambahkan bahwa bidang pengetahuan yang mengalami perkembangan yang baik adalah cabang olahraga, hal ini terbukti dari semakin majunya dalam hal teknik, taktik, dan perlengkapan atau sarana dan prasarana yang sangat menunjang kemajuan dan perkembangan olahraga.

National Paralympic Committee Indonesia yang biasanya disingkat NPCI merupakan organisasi yang memfasilitasi cabang olahraga atlet berkebutuhan khusus di Indonesia. Berdasarkan data dari npcindonesia.id, NPCI awalnya dibentuk dengan nama YPOC (Yayasan Pembina Olahraga Cacat). YPOC dibentuk oleh Prof. Dr. Soeharso pada 31 Oktober 1992 yang didasari karena banyaknya korban perang yang mengakibatkan banyaknya kondisi cacat fisik pada rakyat Indonesia dan kondisi polio yang sedang mewabah di Indonesia. Saat itu belum ada anggaran atau sumber dana dari manapun yang jelas, kemudian dibentuklah YPOC agar pendanaannya jelas. Pada tahun 1996 YPOC sudah tidak berada dibawah naungan KONI (Komite Olahraga Nasional Indonesia) tetapi dibawah naungan menteri sosial sehingga YPOC masih ikut dalam olahraga rehabilitasi dan belum masuk dalam olahraga cacat, hal ini mengakibatkan YPOC tidak berkembang (Haris, Doewes, \& Liskustyawati, 2020). Purdihapsari (2015) mengemukakan National Paralympic Committee of Indonesia (NPC) merupakan induk organisasi yang membantu dan mendampingi Pemerintah Republik Indonesia dalam upaya pembinaan dan pembangunan olahraga prestasi para atlet penyandang disabilitas Indonesia.

Manajemen olahraga adalah suatu proses yang terdiri dari proses prencanaan, pengorganisasian, kepemimpinan, motivasi, komunikasi dan pengambilan keputusan dalam olahraga, sehingga tujuan kita berolahraga dapat tercapai secara efektif dan efisien (Sudarmada 2014). Menurut Nurdiyansah (2018) yaitu prestasi yang di harapkan ini juga meliputi suatu hal yang disebut pembinaan yang dilakukan, sehingga prestasi yang dicapai optimal. Peranan Manajemen dalam masa sekarang perlu dipelajari secara mendalam karena semakin berkembangnya ilmu pengetahuan yang terus meluas serta kemajuan zaman menuntut manusia untuk terus belajar dan terus berkarya agar tidak tertinggal dan tergerus globalisasi. Dalam bidang manajemen perlunya kerja keras untuk memajukan organisasi agar dapat berjalan rapi dan teratur,yang tentunya diperlukan seorang yang mampu berdedikasi tinggi dan bertanggungjawab dalam kegiatan perencanaan,pengorganisasian,penggerak an, serta pengawasan (Haryadi, 2016).

Olahraga bagi penyandang disabilitas dijadikan media untuk mengembangkan potensi dan bakat yang dimiliki, mengingat setiap manusia selain mempunyai kekurangan juga mempunyai kelebihan, kemampuan, dan keunikan tersendiri. Pilihan sebagai atlet bagi para penyandang disabilitas memang dapat dimaklumi karena dengan media olahraga para penyandang disabilitas dapat membuktikan bahwa diriny mampu berkompetisi dan setiap orang berhak mengikuti termasuk para penyandang disabilitas dalam mengeksplorasi bakat keolahragaan yang terpendam dan kemampuan yang dimilikinya, sehingga atlet penyandang disabilitas mampu mengakualisasikan dirinya. Keberhasilan 
aktualisasi diri seorang atlet dapat dilihat pada prestasi-prestasi yang telah dicapainya (Wijayanti, Santi, \& Soegiyanto 2016).

Penelitian ini bertujuan untuk mengetahui manajemen organisasi NPC, prestasi atlet disabilitas, dan factor pedukung dan faktor penghambat dalam pembinaan atlet disabilitas pada NPC Kabupaten Kendal. Wijayanti, Santi, dan Soegiyanto (2016) menyebutkan bahwa prestasi yang ditorehkan oleh penyandang disabilitas melalui bidang olahraga memang cukup menarik untuk dikaji dan dicermati, banyak kalangan mulai dari instansi terkait, pemerhati olahraga sampai masyarakat umum menaruh perhatian pada torehan prestasi mereka. Kepentingan hasil penelitian ini dapat di publikasikan lebih luas untuk ke depannya agar lebih dikenal dan NPC Kabupaten Kendal lebih eksis di kalangan masyarakat karena akademik prestasinya. Hal ini sesuai dengan pernyataan Komaludin (2020) yaitu perkembangan pesat dalam teknologi informasi dan komunikasi berdampak pada pengembangan sumber daya manusia (SDM) memainkan peranan penting sebagai fasilitator dalam menunjang keberhasilan setiap kegiatan operasional perusahaan hal ini dikarenakan perkembangan teknologi, menuntut penguasaan teknologi untuk diaplikasikan dalam aktivitas organisasi, sehingga dapat diperoleh kemanfaatan teknologi tersebut. Penelitian ini dianggap penting karena untuk mengetahui manajemen organisasi dalam pembinaan prestasi atlet disabilitas yang baik, diperlukan penguasaan dan pemahaman untuk memperoleh informasi akurat melalui penelitian ini akan menghasilkan informasi yang maksimal dan terarah sesuai dengan teknologi dan SDM pada NPC Kabupaten Kendal.

\section{METODE PENELITIAN}

Metode penelitian ini adalah jenis penelitian deskriptif kualitatif. Karena hasil penelitian kualitatif berupa deskriptif atau narasi sehingga tidak memerlukan ketelitian penuh untuk melakukan perhitungan. Penelitian deskriptif kualitatif bertujuan untuk menggambarkan, meringkas berbagai macam kondisi, berbagai situasi, dan berbagai fenomena realitas sosial yang ada di masyarakat (Sugiyono 2012). Waktu penelitian dimulai dari bulan Maret sampai Mei 2020. Tempat penelitian dilaksanakan di National Paralympic National (NPC) Kabupaten Kendal yang beralamat di Kelurahan Bungangin RT 4/RW 2 No 29, Kendal. Dimana terdapat obyek dan subyek yang akan diteliti dalam penelitian. Penelitian ini mengambil subjek penelitian Kepala NPC Kendal, Seksi Pemberdaya Atlet, Seksi Cabor \& Pelatih, Atlet Disabilitas. Variabel penelitian ini adalah National Paralympic Committe, Manajemen, Penyandang Disabilitas. Teknik pengumpulan data dengan observasi, wawancara, dokumentasi. Teknik analisis data dengan data collection (pengumpulan data), reduksi data (semua informasi dikumpulkan), sajian data (dalam bentuk kata-kata/wawancara), penarikan kesimpulan/verifikasi (Idrus 2009).

\section{HASIL PENELITIAN}

Perencanaan yang dilakukan oleh National Paralympic Committe (NPC) dalam pembinaan prestasi atlet penyandang disabilitas di Kabupaten Kendal dari program yang dicanangkan yaitu pembinaan untuk atlet disabilitas, pelatihan untuk pelatih guna menambah pengetahuan dan skill meningkatkan penguatan organisasi, menurut Yusuf (2000) program adalah segala sesuatu yang dicoba seseorang dengan harapan akan mendatangkan hasil atau pengaruh. Mendapat dana hibah dari Pemerintah Daerah, serta target untuk iven-iven regional sampai nasional.

Pengorganisasian yang dilakukan oleh National Paralympic Committe (NPC) dalam pembinaan prestasi atlet penyandang disabilitas di Kabupaten Kendal meliputi proses 
penyaringan atlet melalui kerjasama dengan SLB melalui penilaian yang dilakukan oleh guru olahraga SLB dan Tim dari NPC, pemilihan pelatih yang sesuai dengan basic dari lulusan jurusan olahrga, pernah mengikuti latihan dan sertifikat baik pelatih pemula, tingkat lanjut, dan penangan cidera. Menurut Sutarto (2015) suatu organisasi harus memiliki unsur organisasi.

Pelaksanaan yang dilakukan oleh National Paralympic Committe (NPC) dalam pembinaan prestasi atlet penyandang disabilitas di Kabupaten Kendal, NPC melaksanakan perencanaan tahunan dan 5 tahun jadi yang perencanaan tahunan secara rutin sudah berjalan dengan lancar serta disesuaikan dengan kebutuhan ditingkat Provinsi untuk bisa dipadukan kegiatan tersebut dengan tingkat Kabupaten, kendala yang dihadapi mengenai sarana dan prasarana untuk menunjang pembinaan terhadap atlet masih belum seluruhnya memenuhi standar dan untuk mengatasi kendala tersebut pihak NPC mengusulkan anggaran tambahan untuk memenuhi kebutuhan sarpras.

Pengawasan yang dilakukan oleh National Paralympic Committe (NPC) dalam pembinaan prestasi atlet penyandang disabilitas di Kabupaten Kendal dari memantau kondisi atlet, tempat kerja atletnya dan keluarga atletnya agar paham bahwa atlet tersebut berprestasi dan perlu dikembangkan untuk kedepannya, semua pengurus melakukan pengawasan terhadap pelaksanaan pembinaan. Program yang dicanangkan belum sepenuhnya maksimal dikarenakan pendanaan yang masih terbatas dan sarpras masih belum memenuhi standar yang seharusnya, NPC sudah melakukan tindakan perbaikan dengan mengusulkan anggaran lebih untuk sarana dan prasarana guna menunjang pembinaan atlet disabilitas.

\section{PEMBAHASAN}

Mengutip dari hasil penelitian yang dilakukan oleh Wijayanti, Santi \& Soegiyanto (2016) yang menunjukan: (1) pelaksanaan program latihan berjalan walaupun belum semua pelatih menyusun program latihan secara tertulis, (2) pelatih sangat berperan dalam meningkatkan prestasi atlet, namun pelatih banyak yang belum memiliki lisensi pelatih, (3) sarana dan prasarana di NPC Salatiga masih memerlukan perhatian yang khusus, (4) dukungan orang tua atlet secara moral dan spiritual sangat luar biasa sehingga berdampak positif bagi perkembangan prestasi atlet, dan (5) pengurus NPC Salatiga memberikan dukungan terhadap perkembangan prestasi atlet walaupun belum secara optimal karena ada pengurus yang tidak aktif dalam kepengurusan. Sedangkan dari temuan Fabiano (2017) menunjukan pembinaan yang dilakukan mengacu terhadap organisasi paralympic nasional dan proses pembinannya dilakukan secara berkelanjutan. Pembinaan yang dilakukan seperti kepengurusan yang sudah memiliki agenda-agenda kegiatan baik agenda untuk organisasi dan kegiatan untuk olahraga paralympic, serta dukungan atau bantuan pemerintah baik daerah dan pusat juga baik. NPC Indonesia mempunyai sarana latihan seperti bola, net, dumbel, gawang dan sebagainya, yang dalam penggunaannya tidak usah menyewa karena ini adalah milik sendiri. Cabang olahraga atletik NPC indonesia sekarang menjadi penyumbang atlet dan medali paling banyak dalam timnas atlet difabel Indonesia. Prestasi yang dihasilkan juga sangat baik mulai dari tingkat nasional dan internasional.

Tujuan penelitian ini menunjukkan bahwa pembinaan prestasi atlet penyandang disabilitas di Kabupaten Kendal yaitu pembinaan untuk atlet disabilitas, pelatihan untuk pelatih guna menambah pengetahuan dan skill meningkatkan penguatan organisasi. Proses penyaringan atlet melalui kerjasama dengan SLB melalui penilaian yang dilakukan oleh guru olahraga SLB dan Tim dari NPC. NPC melaksanakan perencanaan tahunan dengan kebutuhan ditingkat Provinsi untuk bisa dipadukan kegiatan tersebut dengan 
kegiatan Kabupaten. Pengawasan yang dilakukan oleh National Paralympic Committe (NPC) dalam pembinaan prestasi atlet penyandang disabilitas dari memantau kondisi atlet, tempat kerja atletnya dan keluarga atletnya agar paham bahwa atlet tersebut berprestasi dan perlu dikembangkan untuk kedepannya, menurut Iyus (2007) peran orangtua terhadap prestasi seorang anak mempunyai peranan yang sangat besar. Menurut Rosmi (2016) pendidikan jasmani adaptif yang diajarkan disekolah memiliki peranan yang sangat penting, sehingga penyaringan bibit atlet difabel yang berbobot melalui kerjasama antara guru olahraga SLB masing-masing sekolah dengan tim NPC kabupaten Kendal. Menurut Ferrara, Burns, dan Mills (2015) temuannya memberikan bukti bahwa paralympic setidaknya efek jangka pendek pada sikap terhadap orang-orang cacat. Keterbatasan penelitian ini ada pada faktor pembambat yaitu sarana dan prasarana yang masih belum sesuai dengan kebutuhan dalam proses pembinaan atlet.

\section{KESIMPULAN}

Dari penelitian yang telah dilakukan dapat disimpulkan: (1) yaitu NPC meningkatkan penguatan organisasi melalui rapat koordinasi, memfasilitasi organisasi serta pelaksanaan pembinaan melalui dana hibah dari Pemerintah Daerah, (2) Pembinaan prestasi atlet disabilitas NPC melakukan penyaringan ke SLB guna mencari bibit atlet yang berpotensi, (3) Saran Untuk pemerintah diharapkan lebih sering bersinergi dengan KONI dan NPC untuk mengadakan event/kejuaraan untuk atlet-atlet disabilitas agar olahraga paralympic lebih dikenal oleh masyarakat, serta untuk lebih memperhatikan sarana dan prasarana untuk menunjang pembinaan prestasi agar atlet disabilitas dapat mencapai prestasi yang dapat dibanggakan. Agar kedepannya untuk NPC Kab. Kendal lebih baik dalam membina atlet disabilitas serta manajemen yang lebih bagus untuk SDM, pendanaan, dan program latihan dari pelatih. Untuk peneliti selanjutnya dapat membahas lebih dalam lagi dari manajemen pembinaan di NPC Kab.Kendal ini, serta untuk pemerintah diharapkan lebih bersinergi dengan KONI dan NPC untuk mengadakan event/kejuaraan agar lebih dikenal oleh masyarakat.

\section{DAFTAR PUSTAKA}

Fabiano, K. (2017). Pembinaan prestasi olahraga paralympic cabang olahraga atletik pada persiapan asean paragames ke 9 tahun 2017. Skripsi. Surakarta: Universitas Sebelas Maret.

Ferrara, K., Burns, J., \& Mills, H. (2015). Public attitudes toward people with intellectual disabilities after viewing olympic or paralympic performance. Adapted Physical Activity Quarterly, 32(1), 19-33. https://doi.org/10.1123/apaq.2014-0136

Haryadi. (2016). Studi manajemen pembinaan olahraga sepak bola di klub persatuan sepak bola kota bogor oleh kantor pemuda dan olahraga kota bogor. Jurnal Governansi, 2(1), 45-50. http://dx.doi.org/10.30997/jgs.v2i1.208

Idrus, M. (2009). Metode Penelitian Ilmu Sosial. Yogyakarta: Erlangga.

Iyus, Y. (2007). Keperawatan Jiwa (Ed 1). Jakarta: Refika Aditama. 
Komaludin, D. (2020). Model Manajemen Pengelolaan Pusat Olahraga dan Rekreasi Melalui Pengembangan Sumber Daya Manusia Berbasis Pengetahuan (Knowledge Based Worker). Jurnal Fakultas Keguruan \& Ilmu Pendidikan Kuningan, 1(1), 19-33.

Kresnapati, P. (2020). Perbedaan latihan passing berpasangan dengan perubahan tinggi net berat bola terhadap kemampuan passing bawah. Edu Sportivo: Indonesian Journal of Physical Education, 1(1), 9-15. https://doi.org/https://doi.org/10.25299/es:ijope.2020.vol1(1).5116.

Rusmanto, Lardika, R. A., \& Muspita. (2020). Efektivitas metode resiprokal terhadap keterampilan dasar bermain sepakbola: Studi eksperimen. Edu Sportivo: Indonesian Journal of Physical Education, 1(1), 1-8. https://doi.org/10.25299/es:ijope.2020.vol1(1).5165.

Nurdiyansah, S. (2018). Manajemen Pembinaan Prestasi Olahraga Atletik Klub Sportif Gunungkidul Daerah Istimewa Yogyakarta. Skripsi. Yogyakarta: Universitas Negeri Yogyakarta.

Purdihapsari, N. N. (2015). Manajemen Logistik di National Paralympic of Indonesia (NPC). Skripsi. Surakarta: Universitas Sebelas Maret.

Rosmi, Y. F. (2016). Pendidikan Jasmani dan Pengembangan Karakter Siswa Sekolah Dasar. Wahana: Tri Darma Perguruan Tinggi, 66(1), 55-61. https://doi.org/10.36456/wahana.v66i1.482

Sari, D. N., \& Antoni, D. (2020). Analisis kemampuan forehand drive atlet tenis meja. Edu Sportivo: Indonesian Journal of Physical Education, 1(1), 60-65. https://doi.org/10.25299/es:ijope.2020.vol1(1).5253

Haris, M. A., Doewes, M., \& Liskustyawati, H. (2020). Sistem organisasi atlet nasional boccia cerebral palsy di National Paralympics Committee Indonesia. In Prosiding SENFIKS (Seminar Fakultas Ilmu dan Sains) (pp. 108-117). Universitas PGRI Madiun.

Sudarmada. (2014). Manajemen Olahraga. Yogyakarta: Graha Ilmu.

Sugiyono. (2012). Metode Penelitian Pendidikan (Pendekatan Kuantitatif, Kualitatif dan R\&D). Bandung: Alfabeta.

Sutarto. (2015). Dasar-Dasar Organisasi. Yogyakarta: Gajah Mada.

UU No 3 Tahun 2005. (2005). Undang-Undang Republik Indonesia Nomor 3 Tahun 2005 Tentang Sistem Keolahragaan Nasional. Presiden RI.

Wijayanti, D. G. S., Soegiyanto, S., \& Nasuka, N. (2016). Pembinaan Olahraga Untuk Penyandang Disabilitas di National Paralympic Committee Salatiga.Journal of Physical Education and Sports, 5(1), 17-23.

Yusuf, T. F. (2000). Evaluasi Program. Jakarta: PT. R. Cipta. 